\title{
Hidden diversity in Senegalese bats and associated findings in the systematics of the family Vespertilionidae
}

\author{
Darina Koubínová ${ }^{*}$, Nancy Irwin ${ }^{2}$, Pavel Hulva' ${ }^{1}$ Petr Koubek ${ }^{3,4}$ and Jan Zima ${ }^{3}$
}

\begin{abstract}
Introduction: The Vespertilionidae is the largest family of bats, characterized by high occurrence of morphologically convergent groups, which impedes the study of their evolutionary history. The situation is even more complicated in the tropics, where certain regions remain under-sampled.

Results: Two hundred and thirteen vespertilionid bats from Senegal (West Africa) were studied with the use of non-differentially stained karyotypes and multi-locus sequence data analysed with maximum likelihood and Bayesian methods. These bats were identified as 10 different taxa, five of which were distinctive from their nominate species (Pipistrellus hesperidus, Nycticeinops schlieffenii, Scotoecus hirundo, Neoromicia nana and N. somalica), based on both karyotypes and molecular data. These five cryptic taxa are unrelated, suggesting that these West African populations have long been isolated from other African regions. Additionally, we phylogenetically analysed 166 vespertilionid taxa from localities worldwide using GenBank data (some 80\% of the genera of the family) and 14 representatives of closely related groups, together with our Senegalese specimens. The systematic position of several taxa differed from previous studies and the tribes Pipistrellini and Vespertilionini were redefined. The African Pipistrellus rueppellii was basal to the Pipistrellus/Nyctalus clade and the Oriental species Glischropus tylopus was basal to the East Asian pipistrelles within the tribe Pipistrellini. The African genus Neoromicia was confirmed to be diphyletic. Based on GenBank data, Eptesicus was polyphyletic, with the Asian E. nasutus and E. dimissus both supported as phylogenetically distinct from the Eptesicus clade. The subfamily Scotophilinae was confirmed as one of the basal branches of Vespertilionidae.
\end{abstract}

Conclusions: New taxa and new systematic arrangements show that there is still much to resolve in the vespertilionids and that West Africa is a biogeographic hotspot with more diversity to be discovered.

Keywords: Vespertilionidae, Systematics, Phylogenetics, DNA, Karyotypes, Western Africa

\section{Introduction}

The vespertilionid bats form the largest chiropteran family with approximately 48 genera and 407 species [1]. The representatives of the family are found worldwide, with the highest diversity in the tropics [1]. Due to the occurrence of convergent, parallel or mosaic evolution and the retention of plesiomorphic conditions in several vespertilionid groups, it is difficult to determine the generic status and estimate phylogenetic relationships of many species. Until recently, the phylogenetic relationships of vespertilionid

\footnotetext{
*Correspondence: darina.koubinova@gmail.com

'Department of Zoology, Faculty of Science, Charles University, Viničná 7, 12844 Praha 2, Czech Republic

Full list of author information is available at the end of the article
}

bats were studied mainly through analyses of traditional morphological $[2,3]$ or cytogenetic characters (reviewed in [4-6]), but molecular phylogenetic methods using DNA sequencing have been extensively applied and are changing many traditionally recognized groups (e.g. [7-9]). Some genera have been separated into distinct families (Miniopteridae, Cistugonidae), several tribes were reorganized or even rejected, and a number of cryptic species have also been discovered (e.g. [7-14]). Five subfamilies are currently recognised within Vespertilionidae (Vespertilioninae, Myotinae, Antrozoinae, Murininae, Kerivoulinae and Scotophilinae $[1,15])$, but the number varies from four to eight according to different authors. Based on morphology, the subfamily Vespertilioninae was

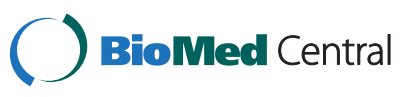


traditionally divided into the tribes Lasiurini, Nycticeiini, Pipistrellini, Plecotini and Myotini [16]. Later, analysis of bacular morphology excluded Scotophilini [17], karyotypes separated Eptesicini [5], with other tribes being Vespertilionini, Nyctophylini and Antrozoini [10]. The genera belonging to these tribes changed their systematic position frequently. Monophyly was supported by karyotypes and studies of mitochondrial DNA only for Lasiurini, Scotophilini and Antrozoini; Myotis was placed in its own subfamily $[5,7,10]$. Based on morphology, the tribe Nycticeiini was thought to include Otonycteris, Rhogeesa, Baeodon, Scotomanes, Scotoecus, Scoteinus, Scotophilus and Nycticeius [16]; however, molecular studies showed a different composition: Glauconycteris, Lasionycteris, Nycticeius, Scotomanes, Eptesicus and Arielulus [7,9,10]. However, Nycticeius position was unresolved with nuclear markers and opened a discussion regarding the appropriateness of the tribal name if it was removed from the group $[9,10]$. Recently, nuclear markers indicated the existence of "perimyotine" (Parastrellus and Perimyotis) and "hypsugine" (Chalinolobus, Hypsugo, Laephotis, Neoromicia, Nycticeinops, Tylonycteris and Vespadelus) groups within Vespertilioninae [10]. The tribe Pipistrellini has also been revised extensively. The tribe was thought to contain Pipistrellus, Glischropus, Scotozous, Nyctalus (supported by karyotypes [5]) and Scotoecus (based on molecular markers [7]). The bacular morphology delimited the Vespertilionini as: Eptesicus, Glauconycteris, Histiotus, Ia, Mimetillus, Tylonycteris and Vespertilio [17]. Later, mitochondrial DNA analysis confirmed inclusion of Hypsugo and Neoromicia (previously belonging to Pipistrellus [17]), while excluding others, e.g. Eptesicus [9]. The genus Scotophilus was traditionally classified within the tribe Nycticeiini $[1,2]$, but has also been placed into Plecotini [18] or Eptesicini [19]. However, bacular morphology [17], mitochondrial DNA [7] and cytogenetic analyses [20] supported the separation of Scotophilus to a distinct tribe Scotophilini. The tribe was elevated to a subfamily rank (Scotophilinae [15,21]) and even proposed to be renamed as Philisinae, based on shared characteristics with the extinct genus Philisis [21].

The systematics of the family Vespertilionidae, especially of some groups, is therefore extremely complicated (see the brief overview of the classification history of the vespertilionids [10]). Even in regions where research effort is extensive, the relationships of many groups still remain unclear. The generic status of the American pipistrelles was clarified only recently [22] and new cryptic species are still being discovered in Europe and Asia (e.g. $[23,24])$. This implies that in other regions, such as tropical Africa, where large geographic areas are undersampled, the systematic classification of vespertilionid bats requires assessment and the evolutionary relationships between species are even less certain.
In Africa, 105 species of vespertilionid bats belonging to 16 genera are currently recognized, thus representing approximately $25 \%$ of the diversity of the family [15]. Despite the long history of zoological surveys on the African continent, knowledge of the bat fauna is patchy and usually targeted to particular regions. Many vespertilionid species lack external taxonomically informative characters and are therefore difficult to identify using morphological keys. Consequently, the possibility of adding new distribution records or even discovering new species is still high [11,25-27].

Western Africa is considered one of the biodiversity hotspots [28]. Senegalese vespertilionids are currently thought to number 50 species [1,15,29-34]; however, this is still likely to be an underestimation. We assessed the diversity of the local vespertilionid bat fauna, focused mainly on the relatively small area (approximately 9,130 sq $\mathrm{km}$ ) of the National Park Niokolo-Koba (inscribed on the List of World Heritage in Danger). Our aim was to identify the species and to understand their systematic relationships within the family. We used a multi-locus approach, sequencing two nuclear (recombination activating gene 1 and 2 - rag1 and rag2) and six mitochondrial genes (cytochrome $b-c y t b, t R N A^{T h r}, 12 S, t R N A^{\text {Val }}, 16 S$ and NADH dehydrogenase subunit $1-n d 1)$. We chose these genes as 1) they are presumed to be informative at different depths in the tree (given their different rates of evolution) and 2) allowed us to make use of previously published sequences of related bat species. These data were analysed with Bayesian analyses (BA) and Maximum Likelihood (ML) methods for inferring phylogeny. To obtain another independent assessment of taxonomic status, we also examined standard non-differentially stained karyotypes from selected specimens.

We identified ten currently recognized species in a sample of 213 bat specimens from Senegal and found five cryptic taxa closely allied to Pipistrellus hesperidus, Nycticeinops schlieffenii, Scotoecus hirundo, Neoromicia nana and $N$. somalica based on molecular systematics and karyotypes. Our findings, based on the Senegalese material and GenBank data of worldwide origin, clarified the phylogenetic position of the African Pipistrellus rueppellii and Asian Eptesicus dimissus, E. nasutus and Glischropus tylopus. We found support for different compositions of the tribes Pipistrellini and Vespertilionini compared to recent publications (see overview in [9]). The tribe Scotophilini was recovered with support as the second most basal branch within the Vespertilionidae and the African genus Neoromicia was confirmed to be diphyletic.

\section{Results}

\section{Cytogenetic analysis}

We obtained non-differentially stained karyotypes for 48 individuals assigned to six species, namely Neoromicia 
somalica, N. rendalli, N. nana, Nycticeinops schlieffenii, Scotoecus hirundo and Pipistrellus hesperidus (Table 1 and Additional file 1). For each species, the diploid number of chromosomes (2n), chromosomal arms number (FN), autosomal arms number (FNa) and morphology of chromosomes was recorded (Table 1). A secondary constriction was noted in all species except Scotoecus hirundo, while Neoromicia somalica was the only species with a bi-armed Y chromosome. The karyotypes of the species currently assigned to Neoromicia shared the number of arms $(\mathrm{FN}=54, \mathrm{FNa}=50)$, but differed in the number of chromosomes. Neoromicia somalica $(2 \mathrm{n}=28, \mathrm{FN}=54, \mathrm{FNa}=50)$ had nine large metacentric and submetacentric, one medium-sized submetacentric, two small subtelocentric and one small acrocentric pairs of chromosomes. The $\mathrm{X}$ chromosome was a medium-sized metacentric, while the $\mathrm{Y}$ was a small submetacentric. A secondary constriction was observed on one pair (no. 7) of large submetacentric autosomes (Figure 1A). The chromosomal complement of Neoromicia rendalli $(2 \mathrm{n}=38$, $\mathrm{FN}=54, \mathrm{FNa}=50$ ) contained six large metacentric and submetacentric, one small subtelocentric and eleven acrocentric pairs. The $\mathrm{X}$ chromosome was a mediumsized submetacentric, while the $\mathrm{Y}$ was dot-like (based on our subjective view, presumably acrocentric). A secondary constriction was recorded on a single pair of acrocentric chromosomes (no. 9; Figure 1B). Neoromicia nana $(2 \mathrm{n}=34, \mathrm{FN}=54, \mathrm{FNa}=50)$ had eight pairs of large bi-armed chromosomes (a large pair of submetacentric chromosomes had a conspicuous secondary constriction no. 8), one pair was small submetacentric and the remaining seven pairs were small acrocentric. The $X$ sex chromosome was a medium-sized subtelocentric, the $\mathrm{Y}$ was dot-like and probably acrocentric (Figure 1C). The analysis of Nycticeinops schlieffenii $(2 \mathrm{n}=34, \mathrm{FN}=56, \mathrm{FNa}=52)$ revealed seven metacentric and submetacentric, one medium large metacentric, two small metacentric and six acrocentric pairs of chromosomes. A distinct secondary constriction was situated on the largest acrocentric pair (no. 11). The X chromosome was a medium metacentric and the $\mathrm{Y}$ chromosome was dot-like in appearance
(Figure 1D). The karyotype of Scotoecus hirundo $(2 \mathrm{n}=30$, $\mathrm{FN}=50, \mathrm{FNa}=46)$ consisted of six large metacentric and submetacentric, three medium-sized bi-armed (submetacentric and subtelocentric) and five acrocentric autosomal pairs of chromosomes. The $\mathrm{X}$ chromosome was a mediumsized metacentric and the Y dot-like, probably acrocentric (Figure 1E). The highest diploid number of chromosomes and chromosomal arms was found in Pipistrellus hesperidus $(2 \mathrm{n}=46, \mathrm{FN}=62, \mathrm{FNa}=58)$, which comprised three large metacentric, two smaller submetacentric, two small submetacentric, and 15 acrocentric pairs of chromosomes (one pair with a secondary constriction - no. 11). The $\mathrm{X}$ chromosome was a medium-sized metacentric and the $\mathrm{Y}$ chromosome was dot-like (Figure 1F).

\section{Molecular phylogenetic analyses \\ Single, mitochondrial and nuclear gene analyses}

Based on the initial ML and BA analyses of the concatenated $c y t b$ and $t R N A^{T h r}$ data from Senegal ([GenBank: JX276105-JX276317]; Additional file 1) and GenBank (Additional file 2; total number of taxa including GenBank data $n=361$, sequence length $=1,212 \mathrm{bp}$ ), we found that the 213 individuals from Senegal represented 10 species assigned to Myotis bocagii $(n=1)$, Neoromicia nana ( $n=98,29$ haplotypes), $N$. somalica ( $n=93,53$ haplotypes), $N$. capensis $(n=1)$, Pipistrellus hesperidus $(n=6,5$ haplotypes), Pipistrellus rueppellii ( $n=2,2$ haplotypes), Scotoecus hirundo $(n=1)$, Neoromicia rendalli $(n=2,2$ haplotypes), Nycticeinops schlieffenii ( $n=8,8$ haplotypes) and Glauconycteris variegata $(n=1$; phylogenetic tree in Additional file 3; haplotypes in Additional file 1). We calculated the $c y t b$ sequence variation using the Kimura twoparameter model of base substitution (K2P) in Phylip version 3.69 ([35]; Additional file 4A) and compared the results with the generally followed genetic criteria for delimiting taxa [36]. The variation between the respective specimens of each Senegalese taxon was less than 1.5\% (Additional file 4A), which is in agreement with the typical intraspecific bat divergence (under 2.3\% [36]).

Selected specimens representing 10 species were sequenced for six additional genes: rag1 (20 individuals,

Table 1 Synoptic list of the main karyotypic characteristics of the 6 species from Senegal and numbers of specimens examined

\begin{tabular}{|c|c|c|c|c|c|c|}
\hline Species & $2 n$ & $\mathrm{FNa}$ & FN & $\mathrm{X}$ & $\mathrm{Y}$ & Specimens analysed \\
\hline Neoromicia nana & 34 & 50 & 54 & ST & $D(A)$ & $9 \hat{0}, 70$ \\
\hline Neoromicia rendalli & 38 & 50 & 54 & SM & $D(A)$ & $2 \hat{\sigma}$ \\
\hline Neoromicia somalica & 28 & 50 & 54 & $M$ & SM & $13 \hat{\delta}, 7 q$ \\
\hline Nycticeinops schlieffenii & 34 & 52 & 56 & $M$ & D & $4 \hat{\jmath}, 10$ \\
\hline Pipistrellus hesperidus & 46 & 58 & 62 & M & D & $3 \hat{\delta}, 10$ \\
\hline Scotoecus hirundo & 30 & 46 & 50 & $M$ & $D(A)$ & $1 \delta$ \\
\hline
\end{tabular}

Abbreviation: Following characteristics are described: $2 n$ diploid number of chromosomes, FNa number of autosomal arms, $F N$ number of chromosomal arms, $M$ metacentric, SM submetacentric, ST subtelocentric, $A$ acrocentric, $D$ dot-like chromosome, $X, Y$ morphology of the sex chromosomes, $\delta$ male, $Q$ female. The brackets indicate the cases when the morphology of the $Y$ chromosome could only be subjectively assumed. 
B

A

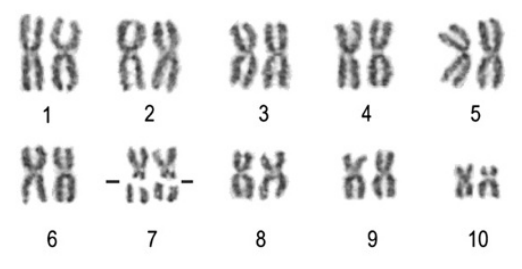

กีล หล

$11 \quad 12$

$\stackrel{\cdots}{13}$

\&.

$X Y$

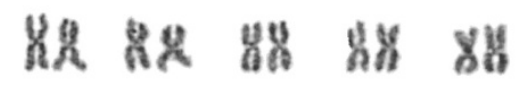

$\begin{array}{lllll}1 & 2 & 3 & 4 & 5\end{array}$

th

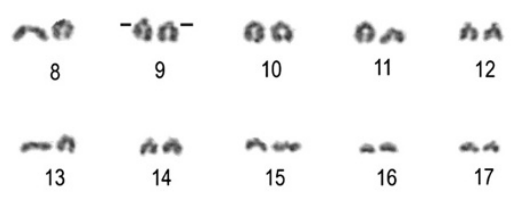

$n$

18
K.

$X Y$

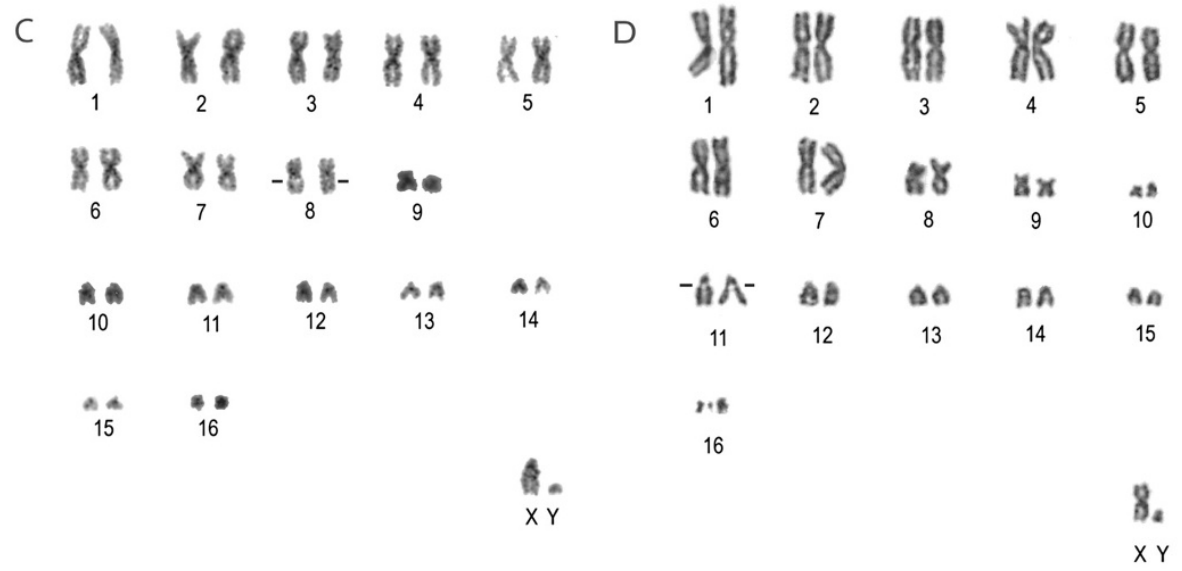

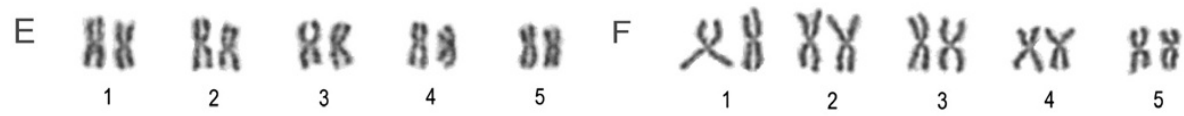

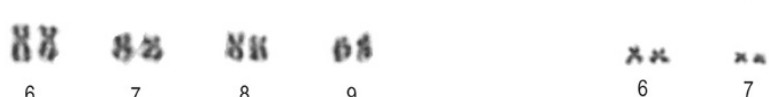

$\begin{array}{llllll}6 & 7 & 8 & 9 & 6 & 7\end{array}$

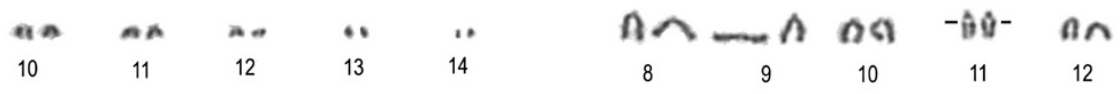

$\begin{array}{lccccc}\text { 8. } & \text { NA } & \text { nA } & \text { คิ } & \text { กn } & \text { - A } \\ X Y & 13 & 14 & 15 & 16 & 17\end{array}$

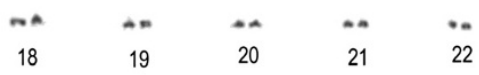

$x$.

$X Y$

Figure 1 Male karyotypes of the vespertilionid species studied. A - Neoromicia somalica, IVB S1209 (secondary constriction on the seventh pair of chromosomes); B - N. rendalli, IVB S1212 (secondary constriction on one pair of acrocentric chromosomes - number nine); $\mathbf{C}-\mathrm{N}$. nana, IVB S1210 (secondary constriction on the pair number eight); D - Nycticeinops schlieffenii, IVB S1378 (secondary constriction on the pair number 11); E - Scotoecus hirundo; IVB S1480, F - Pipistrellus hesperidus, IVB 5592 (secondary constriction on the eleventh pair of chromosomes). The small black lines indicate the positions of the secondary constriction (even if not visible in both of the presented chromosomes of the respective pairs). 
[GenBank: JX276320-JX276339]), rag2 (20 individuals, [GenBank: JX276340-JX276359]), 12S, tRNA ${ }^{\text {Val }}$ and $16 S$ (18 individuals, [GenBank: JX276360-JX276377]), and $n d 1$ (2 individuals, [GenBank: JX276318-JX276319]; Additional file 1). These individuals were used in subsequent ML analyses of single genes and combined mitochondrial $\left(c y t b+12 S+t R N A^{\text {Val }} ; \mathrm{ML}, \mathrm{BA}\right)$ and nuclear genes (rag1 + rag2; ML) analyses. In the $12 S$ tree, G. variegata was sister to $G$. beatrix (bootstrap support $B S=86$ ), and both these species were related to a clade consisting of $G$. argentata and G. egeria $(\mathrm{BS}=100$; Additional file 5A). Yet, in the nuclear gene tree (concatenated rag1 and rag2), Glauconycteris variegata was basal to all Glauconycteris (BS = 100; Additional file 5C).

To test the influence of phylogenetic methods used on the position of Pipistrellus rueppellii, we reanalysed the $n d 1$ dataset (900 bp, $n=217$; originally analysed with Neighbour-joining (NJ) and Kimura 2-parameter distances) of Mayer et al. [37] with ML and Bayesian methods. Pipistrellus rueppellii was basal (together with P. nathusii) to the Pipistrellus/Nyctalus clade ( $\mathrm{BS}=74$, Bayesian posterior probabilities $\mathrm{PP}=1$; Additional file 6), a position similar to the phylogenetic analyses of the concatenated genes of this study (see results below).

\section{Multi-locus analysis of eight genes}

The phylogenetic analyses of the combined dataset using ML and BA resulted in similar topologies (eight genes; 20 specimens of 10 Senegalese species; 180 taxa from GenBank; Accession numbers listed in Additional file 1 and Additional file 2). There was no node that was statistically supported in a different position in different analyses (the only exception was the weak support of Glauconycteris, see below). The Bayesian phylogram with proportional branch lengths and confidence for the nodes recovered by both phylogenetic methods (PP and BS) is presented (Figure 2, if not stated differently, all the following results refer to this figure and to both methods).

Five species from Senegal were not distinctive from individuals from other African localities (Myotis bocogii, Neoromicia nana, N. rendalli, Pipistrellus rueppellii and Glauconycteris variegata). However, the other five Senegalese taxa differed from their putative species - Pipistrellus cf. hesperidus, Nycticeinops cf. schlieffenii, Scotoecus cf. hirundo, Neoromicia cf. nana and N. cf. somalica (Figure 2). The genetic distance for cytb between Pipistrellus cf. hesperidus, Neoromicia cf. nana and N. cf. somalica and its respective "conspecific" from other populations was large 4.79-13.18\% (Additional file 4A). No comparable cytb sequences were available for the two other taxa, but the differences for other genes were also large. Nycticeinops cf. schlieffenii from Senegal differed from its conspecifics by $5.56-5.91 \%$ for $12 S$. The $12 S$ divergence between the remaining available taxa from Senegal and respective
GenBank samples from other populations was about $1.87-6.26 \%$ for the cryptic taxa and less than $1 \%$ for the others (Additional file 4B). The genetic divergence between the Senegalese and the Tanzanian specimen of Scotoecus hirundo was $1.6 \%$ for rag2 which is relatively high (the range of "non-cryptic" taxa was $0-0.68 \%$; Additional file 4C).

Based on both Senegalese and GenBank data, we found support for the composition of the tribes Pipistrellini (Nyctalus, Pipistrellus, Scotoecus and Glischropus) and Vespertilionini (Neoromicia, Laephotis, Hypsugo, Vespadelus, Nycticeinops, Tylonycteris, Eptesicus dimissus, Vespertilio and Chalinolobus). In the Pipistrellini, where Senegalese specimens were also included in the analysis, Pipistrellus rueppellii was well supported in a basal position within the Pipistrellus/Nyctalus clade $(\mathrm{PP}=1, \mathrm{BS}=93)$ and Scotoecus hirundo was basal to this whole group $(\mathrm{PP}=1, \mathrm{BS}=100)$. Pipistrellus hesperidus appeared clearly distinct from its sister group containing $P$. kuhlii $(\mathrm{PP}=1, \mathrm{BS}=85)$. The Asian species Glischropus tylopus (data only from GenBank) was included within the Pipistrellini, as basal to the clade of the East Asian species of Pipistrellus (P. coromandra, P. tenuis, $P$. paterculus, $P$. stenopterus, $P$. javanicus and $P$. abramus) with reasonable support $(\mathrm{PP}=0.97, \mathrm{BS}=74)$. In the tribe Vespertilionini, the genus Hypsugo was polyphyletic. Nycticeinops schlieffenii (including individuals from Senegal) was sister to Hypsugo eisentrauti $(\mathrm{PP}=1, \mathrm{BS}=85$ ), while $H$. cadornae and $H$. savii formed a distinct group related to the Chalinolobus /Vespadelus clade $(\mathrm{PP}=1, \mathrm{BS}=81)$. The analyses included west-African specimens belonging to several species assigned to Neoromicia. Neoromicia nana was related to $N$. brunnea and $N$. rendalli in single gene trees and in the trees based on the concatenated nuclear genes (cytb, Additional file 3; rag1 + rag2, Additional file $5 \mathrm{C})$. In the tree based on the eight genes, Neoromicia nana formed a clade with $N$. brunnea and $N$. rendalli $(\mathrm{PP}=1, \mathrm{BS}=90)$, whereas, $N$. somalica and $N$. capensis showed close relationship to Laephotis $(\mathrm{PP}=1, \mathrm{BS}=100$; Figure 2).

In the tribe Eptesicini, one of the species occurring in Senegal, Glauconycteris variegata was found basal within the Glauconycteris clade only in the $\mathrm{ML}$ analysis $(\mathrm{BS}=79)$. In the BA, the result was likely influenced by Arielulus cuprosus, which appeared in the Glauconycteris clade (unsupported). The genus Eptesicus (based only on published sequences) was polyphyletic. Both Asian $E$. nasutus and E. dimissus were clearly distinct from the Eptesicus clade. Eptesicus dimissus was sister and basal to Tylonycteris $(\mathrm{PP}=1, \mathrm{BS}=100)$ within the tribe Vespertilionini; whereas E. nasutus was basal to both the clades Vespertilionini and Pipistrellini $(\mathrm{PP}=1, \mathrm{BS}=74)$. Nycticeius humeralis (data only from GenBank) was one of the basal taxa of a clade that included Glauconycteris, Hesperoptenus, Arielulus and Lasionycteris. However, 

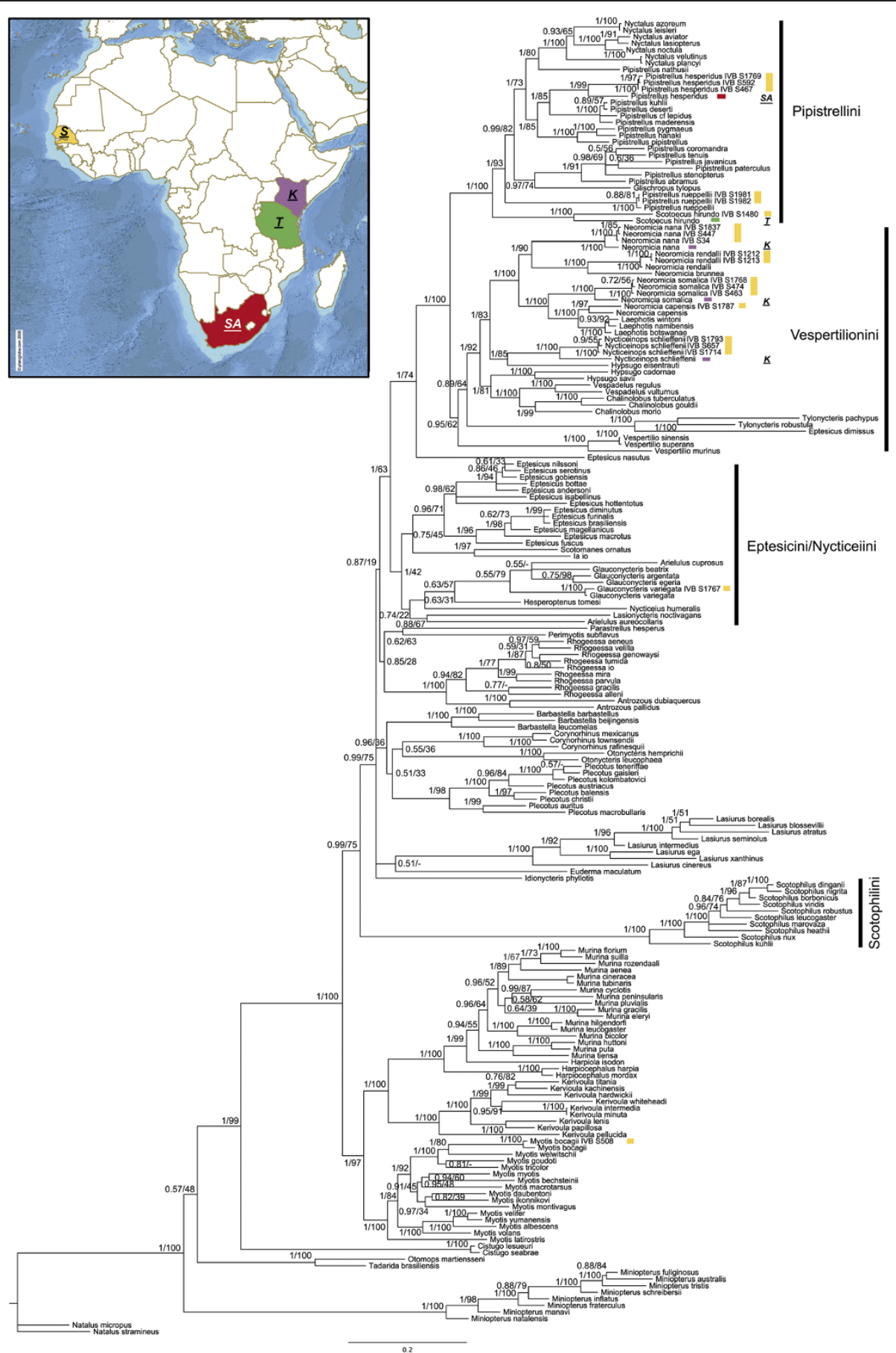

Figure 2 Phylogenetic tree. Phylogram of vespertilionid bat species from Senegal (IVB S) and GenBank data with selected tribes indicated. A Bayesian phylogenetic tree based on the concatenated dataset of 6 mitochondrial and 2 nuclear genes $\left(c y t b+t R N A^{\text {Thr }}+12 S+t R N A^{\mathrm{Val}}+16 S+n d 1+\right.$ rag 1 rag2; 5,665 bp; total $n=200$ ) is presented. Nodes supports are indicated by posterior probabilities and/or bootstrap values resulting from $\mathrm{ML}$ analysis of the same dataset (BA values are left and ML values right of the hashes). Nodes, which were not supported with ML and were in different position than in BA, are indicated with "-". Nodes are considered supported when Bayesian posterior probabilities are $\geq 0.95$ and/or ML bootstrap proportions are $\geq 75 \%$. The bar indicates genetic distance (the number of nucleotide substitutions per site). The map of Africa, shows the sampling localities of the five taxa considered to be cryptic in Senegal. The map shows the position of Senegal $(\boldsymbol{S})$ and the countries, where the specimens from GenBank, used here for the genetic distance comparison, were sampled: $\underline{S} \boldsymbol{A}$ - South Africa (Pipistrellus hesperidus), $\underline{\boldsymbol{T}}$ - Tanzania (Scotoecus hirundo), $\boldsymbol{K}$ - Kenya (Neoromicia somalica, Nycticeinops schlieffenii, Neoromicia nana). The same symbols and colours are used to show the origin of the respective specimens in the phylogram. 
there was little support for the intra-relationships within this clade, sister to a clade that contained Eptesicus (except for E. nasutus and E. dimissus), Scotomanes and Ia $(\mathrm{PP}=1, \mathrm{BS}=42)$.

The tribe Scotophilini was supported as the second most basal branch within the vespertilionid bats $(\mathrm{PP}=0.99$, $\mathrm{BS}=75$ ). In the Myotini, Myotis bocagii represented a sister branch to $M$. welwitschii within the Ethiopian clade of the genus Myotis ( $\mathrm{PP}=1, \mathrm{BS}=80)$.

\section{Discussion}

Phylogenetic relationships of the family Vespertilionidae are an area of active research (e.g. [7-10,38]). Our results from West African populations have found evidence of cryptic taxa and clarified several phylogenetic relationships within the vespertilionids, as well as supported certain tribes contrary to some recent molecular taxonomic systematic discussions [10,12,39].

\section{Karyotypes}

We found differences in the diploid chromosome numbers and/or in chromosome morphology between the populations from Senegal and other regions of Africa in four out of six bat species examined (Neoromicia cf. somalica, $N$. cf. nana, Scotoecus cf. hirundo and Pipistrellus cf. hesperidus) and divergence to at least some African populations in one (Nycticeinops cf. schlieffenii).

The karyotype of $N$. somalica from Senegal contained one additional pair of acrocentric autosomes compared to the $N$. somalica from Cameroon $(2 \mathrm{n}=26, \mathrm{FNa}=48$ [40]). It also differed from the karyotype of $N$. zuluensis (previously included in N. somalica; see $[2,41]$ ) from southern Africa $(2 \mathrm{n}=28, \mathrm{FNa}=48$ [41]) and South Africa $(2 \mathrm{n}=28$, $\mathrm{FNa}=50$ [38]). Despite sharing the same diploid number with $N$. zuluensis, $N$. somalica had a different structure of some bi-armed chromosomes and the $\mathrm{X}$ chromosome was metacentric in $N$. somalica, while being subtelocentric in $N$. zuluensis $[38,41]$. Thus, this is the first finding of a karyotype with a metacentric $\mathrm{X}$ chromosome within the $N$. somalica/zuluensis complex. Additionally, from the populations examined in southern Africa, the Senegalese specimens differed in the number of acrocentric autosomes (one pair - this study; two pairs [41]).

The Senegalese specimens of Neoromicia nana lacked two pairs of acrocentric autosomes compared to previous findings, but the karyotype contained an additional metacentric pair, which could have arisen by a Robertsonian fusion of the two acrocentric pairs. The $\mathrm{X}$ chromosome was subtelocentric, while it was metacentric in other studies $(2 \mathrm{n}=36, \mathrm{FN}=50[38,41,42])$. The karyotype of $N$. rendalli from Senegal is very similar to those found in populations from Somalia [40], Zimbabwe [43] and Southern Africa [38]. The only difference was in the relative size and morphology of the sex chromosome X. In Senegal it was conspicuously smaller than in the Somalian and Zimbabwean specimens, and it was submetacentric, while in Southern Africa it was metacentric. The diploid chromosome numbers of $N$. nana, N. brunnea and $N$. rendalli range from 34 to 38 , with a stable $\mathrm{FNa}=50$ (this study; [40]). However, other members of this clade are reported to have karyotypes with lower numbers of chromosomes: $N$. capensis $-2 \mathrm{n}=32, \mathrm{FNa}=50[4,38,41,42]$ and Laephotis botswanae, namibensis and wintoni $-2 \mathrm{n}=34$, $\mathrm{FNa}=50$ [41]. Thus, the non-differentially stained karyotypes were not helpful in distinguishing the deeper relationships within the clade detected by molecular data.

Nycticeinops schlieffenii found in Senegal was karyotypically similar to findings from Somalia [44], while being conspicuously different in the number of chromosomes and chromosomal arms from the Southern African populations $(2 \mathrm{n}=42, \mathrm{FNa}=50$ [41]), thus confirming the existence of two distinct species in Africa [15]. The karyotype of Scotoecus hirundo from Senegal $(2 \mathrm{n}=30, \mathrm{FN}=50$, $\mathrm{FNa}=46$ ) had a reduced number of arms than reported previously from the Ivory Coast $(2 \mathrm{n}=30, \mathrm{FN}=54$, $\mathrm{FNa}=50[20]$ ), thus indicating that the specimen from Senegal may also represent a distinct species.

All specimens from the Senegalese populations of Pipistrellus hesperidus had a higher diploid number of chromosomes $(2 \mathrm{n}=46, \mathrm{FNa}=58)$ than specimens from South Africa and Madagascar $(2 \mathrm{n}=42, \mathrm{FNa}=50[4,38,41])$. The three smallest chromosomal pairs of the Senegalese specimens that are additional to other karyotypes of $P$. hesperidus could be supernumerary B-chromosomes that consist of only heterochromatic material. If this was the case, the presence of B-chromosomes could be proved by banding methods (which was not possible here, see Material and Methods), or by discovering a specimen with an odd chromosome number. All specimens examined had $2 n=46$ in all 5-10 cells that were analysed for each specimen. We are therefore confident that $P$. hesperidus from Senegal has a different karyotype.

The variability of chiropteran karyotypes occurs relatively rarely [41], which is in contrast with e.g. rodents and shrews [45]. Despite some taxa having conservative karyotypes, Vespertilionidae as a whole are quite karyotypically diverse (see review in $[4,6,41]$ ). It has been therefore hypothesized that each species may be characterized by a distinct karyotype [4]. The occurrence of intraspecific variability, as seen here in some species, supports the hypothesis that these taxa represent cryptic forms [4,41]. The role of chromosomal rearrangement in reducing gene flow between races has been an area of active research for decades (reviewed in [46]). Recent evidence suggests that gene flow is not always impeded between forms with different karyotypes [47]. However, the differences found between the karyotypes of the hypothetical cryptic taxa from Senegal and their nominal species are 
supported with other lines of evidence such as molecular sequence data and morphological characters (see also discussion below).

\section{Molecular phylogeny of Senegalese specimens}

The Senegalese specimens of Pipistrellus rueppellii can be confidently assigned to $P$. $r$. senegalensis, which is distributed from Algeria to Senegal (type locality Richard-Toll in Senegal $[2,32]$ ). They were large (forearm length $=33.3$, $35.8 \mathrm{~mm}$ ) relative to other non West African races [48] and were genetically similar to Moroccan samples ( $n d 1$; [37]). However, contrary to previous results from Morocco [37] and Sardinia [49], the Senegalese P. rueppellii formed a well-supported long branch that was basal in the Pipistrellus/Nyctalus clade. We, therefore, re-analysed the complete published $n d 1$ data of Mayer et al. [37] with $\mathrm{ML}$ and BA and again recovered the basal position of $P$. rueppellii, confirming the differences between studies were due the different analytical approaches used ( $\mathrm{PP}=1, \mathrm{BS}=74$; Additional file 6). The simple algorithm based methods such as neighbour joining used by Mayer et al. [37] may be biased by long-branch attraction [50]. Bayesian inference of phylogeny is especially useful in such cases, as it is capable of finding global rather than local optima during heuristic searches [51]. The discrepancy between our results and Veith et al. [49] is likely to be due to differences in the datasets as they used less taxa and only very short fragment of $16 \mathrm{~S}$ (different to ours; $560 \mathrm{bp}$ ).

The unique position of $P$. rueppellii within the tribe was also demonstrated by the large genetic distinctiveness to other related species. The $c y t b$ divergence to six Eurasian and one African Pipistrellus species was between $19.59-24.07 \%$ and to Scotoecus hirundo it was $22.71-26.33 \%$. The inter-species variation of the other Pipistrellus species was between 4.19-23.29\% (Additional file 4A). The mean observed genetic variation between sister taxa of Pipistrellus is $6.7 \%$ (3.3-14.7\% in all bats) and for non-sister species (inter-generic) some 10.6-16.5\% (8.4-15.7\% for bats in general [36]). These divergences therefore support the hypothesis that $P$. rueppellii is a member of a distinct genus. In agreement with this finding, $P$. rueppellii sensu stricto has been previously classified in the subgenus Vansonia [52] and differences to other Pipistrellus-like bats were also noted in a recent morphological study [53]. Comparison with the type specimen of $P$. vernayi (synonym to $P$. rueppellii) from Maun, Ngamiland, Botswana [54], which is the type species of Vansonia [15], showed that the Botswanian sample had smaller ears (12 mm versus approximately $15 \mathrm{~mm}$ here) and tragus ( $4 \mathrm{~mm}$ versus $5.5 \mathrm{~mm}$ here). The other (cranial and external) measurements were similar. Only further sampling of specimens from the type country, Sudan (see [1]), and the type locality of $P$. vernayi [15], together with a full taxonomic treatment, will be able to resolve both the species and generic status of this species.

Pipistrellus hesperidus from Senegal was distinct from P. kuhlii as had been shown previously $[4,38,55]$. Three different subspecies, which may deserve elevation to species rank, are recognized in the $P$. hesperidus complex [1]: hesperidus (North-eastern Africa), fuscatus (Afro-tropical regions other than Southern Africa and Madagascar) and subtilis (Southern Africa and Madagascar). Pipistrellus fuscatus has also been recognized as synonymous to hesperidus with an additional subspecies $P$. h. broomi recognized in the populations from South Africa [15]. The Senegalese specimens of $P$. hesperidus were 13\% divergent in cytb (Additional file 4A) to P. hesperidus from South Africa [13]. While it is not surprising that geographically distant populations are genetically divergent, divergence of this order is usually considered at least inter-specific [36]. The Senegalese $P$. cf. hesperidus therefore is likely to represent a distinct taxon from $P$. hesperidus sensu stricto (type locality Eritrea, Abyssinia, shores of the Red Sea [15]). However, without comparable material it is not possible to confirm if these samples represent one of the already named subspecies (see [1]) or a completely new species.

We confirm Scotoecus (S. hirundo) as sister to the Pipistrellus/Nyctalus clade $[9,10]$ and therefore the validity of its inclusion in the tribe Pipistrellini, and not within Nycticeiini as previously thought $[7,17,20]$. Mitochondrial sequences from other $S$. hirundo are not available. However, the genetic divergence between the Senegalese and the Tanzanian specimen was $1.6 \%$ for rag2 (Additional file 4C; [10]), which is relatively high. The uniqueness of the Senegalese specimens was also confirmed by the different karyotypes (compare with [20]). The specimens from both studies originated from Western Africa (Senegal, this study; Ivory Coast [20]), close to the type locality in Ghana [15]. Therefore, there are certainly two cryptic populations in West Africa, but more sampling is needed to determine which one represents the nominotypical species.

The polyphyly of Neoromicia and the separation of this genus into two lineages (the first containing $N$. somalica, $N$. capensis and Laephotis and the second containing $N$. nana, N. brunnea and N. rendalli) confirmed previous results $[7,11,13]$. Previously, Laephotis was found related to some Neoromicia species on the basis of bacular morphological characters [38]. Later, it was suggested to retain the name Neoromicia for N. somalica and to allocate nana, brunnea and rendalli to a separate, as yet unnamed, genus [7]. Neoromicia nana and N. somalica from Senegal were karyotypically distinct and also divergent in cytb (8-9\% and 5\%) from their respective conspecifics from Kenya [7]. These specimens are therefore likely to represent new taxa. Despite many revisions of the Neoromicia group (see review in $[1,15])$, the taxonomic status of the genus and species are 
still not successfully resolved and require further systematic work using samples from a wider geographic distribution.

Nycticeinops schlieffenii is distributed in three areas in Africa; the West, the East and South [15]. Molecular systematics separated the East and West populations at a species indicative level (more than 5\% divergence for $12 S$, this study; [7]), despite sharing similar karyotypes (this study; [44]). Moreover, southern populations have different karyotypes to the East/West populations (this study; $[41,44])$. The Eastern populations seem to be similar to the type from Egypt [15], but further taxonomic work is required to delimit the type's distribution and correctly describe all the taxa. Glauconycteris variegata was supported in different positions within the genus based on the genes and/or methods used. Nuclear markers placed G. variegata as the basal species (from 4 used out of 12 described [1]); directly opposing a hypothesis based on the karyotypes where it was thought to be the derived state for the genus [56]. The basal position was only weakly supported $(\mathrm{PP}=0.55, \mathrm{BS}=79)$ in the concatenated dataset (Figure 2). Phylogenetic analysis using a larger dataset placed G. variegata as sister to G. argentata and G. egeria, while G. beatrix was basal [9]. The sequences used here are all taken from Roehrs et al. [9] with only the addition of the Senegalese $G$. variegata that was not very variable from the Kenyan samples (Additional file $4 \mathrm{~B}$ and Additional file 4C; [9]). Different taxon sampling or missing data could have caused the differences, but Roehrs' result supported by a larger dataset $(8,124 \mathrm{bp})$ is more probable.

\section{Molecular systematics of vespertilionids}

The systematic relationships of vespertilionids revealed here were topologically similar to recent assessments (e.g. [7-10]); however, some phylogenetic positions were significantly different. We clarify the tribe containing Glischropus, two species previously assigned to Eptesicus, redefine the tribe Pipistrellini and Vespertilionini and clarify the position of the tribe Scotophilini. This tribe was demonstrated as basal to other vespertilionid bats based on $m t$ DNA phylogenies (this study - Additional file 5A and Additional file 5B; [13,21,39]), but was supported as sister to Antrozoini using combined multi-locus datasets $[9,10]$. Our results place Scotophilini as the second most basal branch within all vespertilionids with reasonable support $(\mathrm{PP}=0.99, \mathrm{BS}=75)$, similar to the phylogeny presented by Lack and Van Den Bussche [57]. The combined evidence from all recent studies confirms that Scotophilini are clearly distinct from other Vespertilionidae and deserve a full subfamily rank (Scotophilinae; or Philisinae, see Introduction and $[15,21])$.

Glischropus tylopus was significantly supported in Pipistrellini, within the clade of the East Asian pipistrelles. These results agree with cytogenetic data that placed Glischropus in Pipistrellini together with Pipistrellus,
Nyctalus (and Scotozous, which is now excluded [4]), and previous molecular studies (unsupported [58]). The concatenated dataset confirmed the close relationship of P. nathusii to Nyctalus ( $\mathrm{PP}=1, \mathrm{BS}=80$; Figure 2 ; $[7,10]$ ), in contrast to the most recent assessment (16S; [49]) and our results ( rag genes or combined $c y t b$ and $t R N A^{T h r}$ genes; Additional file 3 and Additional file 5C), where it appeared in other (even basal) positions within the Pipistrellus/ Nyctalus clade. Glischropus with Nyctalus represent two genera that are morphologically distinguishable from Pipistrellus $[59,60]$, but nest phylogenetically within this genus (this study; [7]). Systematically, this leaves Pipistrellus as diphyletic, which requires further investigation.

Eptesicus dimissus was related to Tylonycteris within the Vespertilionini and not to other Eptesicus species in Eptesicini. Previously, Eptesicus dimissus appeared either basal to Pipistrellus (maximum likelihood $\mathrm{BS}=70$, $\mathrm{PP}=1.0$ ), sister to Hypsugo cadornae (maximum parsimony $\mathrm{BS}=90$ [8]), or sister to Tylonycteris [57]. Here, it was strongly supported as sister to Tylonycteris (Figure 2). Likewise, E. nasutus was previously found distinct from the Eptesicus clade, but its exact position remained unsupported [61]. It has also been assigned to the subgenus Rhineptesicus [62], but this was later refuted [1,15]. Here, it was significantly distinct from Eptesicus and basal to Vespertilionini and Pipistrellini ( $\mathrm{PP}=1, \mathrm{BS}=74$; Figure 2). Eptesicus dimissus and E. nasutus are rarely caught, but their phylogenetic distinctiveness to Eptesicus confirms this genus needs to be taxonomically revised.

Roehrs et al. [10] suggested using the name Vespertilionini for a tribe that only included Nyctalus, Pipistrellus, Scotoecus and Vespertilio (previously Pipistrellini). Here, the tribe Vespertilionini (as used by [5]) appeared well supported (Vespertilio, Neoromicia, Hypsugo, Chalinolobus, Laephotis, Nycticeinops, Tylonycteris, Eptesicus dimissus and Vespadelus). These taxa have been described as the hypsugine group [10], but were previously recognized as Vespertilionini [5,7]. Our evidence supports retaining the following names for the respective tribes, i.e. Pipistrellini for Nyctalus, Pipistrellus, Scotoecus and Glischropus (similarly as recognized by $[1,4,7,60]$; but excluding Perimyotis and Parastrellus) and Vespertilionini, i.e. Vespertilio, Neoromicia, Hypsugo, Chalinolobus, Laephotis, Nycticeinops, Tylonycteris, Eptesicus dimissus and Vespadelus (similarly as recognized by [7]).

Nycticeius humeralis appeared in a clade that contained members from the genera Eptesicus, Scotomanes, Lasiurus, Arielulus, Glauconycteris, Hesperoptenus and Lasionycteris. However, this position was supported only in the tree based on combined mitochondrial genes (Additional file 5B; $\mathrm{PP}=0.95$ ). If this topology (similar to [9]) approaches the truth, it would require the tribe to be recognized as Nycticeiini, rather than Eptesicini on the basis of priority [9]. These taxa form long branches and, short of 
increasing taxon sampling, it may be that more data via Next Generation sequencing will be necessary to clarify these deep relationships.

\section{Conclusions}

Phylogenetic analysis of the vespertilionid bats from Senegal have highlighted how little is known about the bat fauna of the region. Five taxa different enough to be considered new (cryptic) species under the genetic [36] and phylogenetic species concepts were detected (Pipistrellus cf. hesperidus, Nycticeinops cf. schlieffenii, Scotoecus cf. hirundo, Neoromicia cf. nana and N. cf. somalica). Despite the known limitations of the genetic species concept [63], all these findings are additionally supported by karyotypical divergences. Clearly a full taxonomic assessment is required to determine if there are hidden morphological characters that would support the delimitation of these species. The presence of cryptic (morphologically similar, but genetically and phylogenetically distinct) taxa pairs across the tree of Vespertilionidae suggests a signal of long genetic isolation between West- and other African populations (probably about 0.4-6 million years ago at species level, compare with $[13,64])$. The studies of past climatic oscillations in subtropical Africa are not numerous, but there is good evidence of periodic shifts from drier to more humid conditions during the Pliocene-Pleistocene transition, at the same time as shifts between glacial and moderate climate conditions at higher latitudes [65]. One of the arid periods and subsequent decrease of tree cover (1.8-1.6 Mya) is evidently related to taxonomic diversifications at species level in some western and central African forest pteropodids, while the intraspecific divergences based on standard mammalian rate of evolution probably appeared at the end of Pleistocene (about 0.1-0.4 Mya [64]). This is similar for the African Myotis, where population divergence is recent (Pleistocene), but species diversification occurred earlier, at about 6 Mya [13] when aridity caused massive steppe expansion across tropical Africa [66]. Late Pleistocene and Holocene refugia have been hypothesized along the Atlantic coast of western Africa for several west and central African plants and rodents $[67,68]$. Similar refugia have been detected in eastern, central and southern parts of Africa, for both small and large mammals inhabiting forest or savannah [69]. Three Senegalese taxa could be roughly dated from their conspecifics (based on the mean mammalian cytb sequence evolution rate adjusted for bats to about 0.02-0.05 per lineage per 1 million years and results of other works on African bats [13,64]). The split between Neoromicia cf. somalica and N. cf. nana from Senegal and respective populations from east Africa dated to $3.2 \mathrm{Mya}$ and Pipistrellus cf. hesperidus split from South African populations at around 4.2 Mya. The divergence of $P$. hesperidus would therefore have occurred sometime during the Pliocene's long trend of forest expansion while the Neoromicia species divergence corresponds with the time known as the onset of a dramatic tree cover decline in the region [66]. One of the well-established biogeographic barriers responding to the fluctuations of past climate changes between the rainforests of East and West Africa is the so-called Dahomey Gap [68]. Today it is some $200 \mathrm{~km}$ wide, but is known to have closed and opened through time (probably in relation to the arid/humid periods [70,71]). This savannah corridor represented a dispersal barrier for many forest-dwelling species [70,72,73], but mammalian and bird species inhabiting savannahs and more arid regions have also shown high genetic differentiation between north/west and south/east African populations [74-76]. Bats are hypothesized to be able to cross the Dahomey Gap [64,77,78]; but establishing populations within the gap would be unlikely for forest-dwelling species with small ranges [64,79]. Moreover, the Niger Delta or the Cameroon volcanic line have also been hypothesised to act as environmental barriers for some pteropodid populations from West and Central Africa [64]. There are few data across Africa to truly assess distributions and habitat type preference of the species examined here $[1,15,29]$ and without denser sampling we are really limited in the conclusions that can be drawn. The mechanism determining speciation in each species will depend on many factors, including ecology, flight abilities and home-range fidelity, as well as exposure to abiotic, vicariant or climatic events. Further studies are therefore required to understand how population ecology and dispersion contribute to gene flow and to the diversification of vespertilionids in the region.

West Africa (especially the forest zone, up to the Nigeria/ Cameroon boarders) is recognised as a region with high number of endemic organisms and as among one of the most fruitful parts of the continent for describing new cryptic taxa [80]. Recently, new species have been found within rodents, reptiles and insects $[73,81,82]$. Likewise, cryptic forms and new chromosomal races were detected in Senegal and other parts of Western Africa in pteropodid, rhinolophid, hipposiderid and vespertilionid bats (this study; $[11,64,83-85]$ ). This makes this area a hotspot for further chiropteran species discovery, and is in agreement with a general view that West Africa is one of the world's key hotspots of biodiversity [28].

New taxa and new systematic arrangements together with support from karyotypes demonstrate that there is still much to uncover in the vespertilionids and that morphologically similar species that occur in Africa are a result of convergent evolution and belong to phylogenetically distant groups. Morphologically distinct species can be ecologically and even genetically very similar and vice versa - closelyrelated species may be morphologically undistinguishable 
while being different in ecology and echolocation calls, as a consequence of convergent adaptive evolution [86,87]. Cryptic taxa with little morphological characteristics are an increasingly common phenomenon in Pipistrellus-like bats and genetic data are the most powerful tool for distinguishing them reliably $[36,86]$. Considering the frequent occurrence of hybridization and introgression in rapidly evolving lineages, including bat species of this group [88], both mitochondrial and nuclear data are necessary to make phylogenetic inference on historical relationships. While there is still a taxonomic impediment to provide keys and aid ecological work on these species, molecular systematics in conjunction with an independent character state such as karyotypes has confirmed several taxa as distinct and greatly adds to our understanding of biogeographic history of this diverse group of bats.

\section{Material and methods}

\section{Sampling and localities}

Two hundred and thirteen vespertilionid bats were obtained during seven expeditions to Senegal (Western Africa) between 2004-2008 from 20 collection sites mainly in the Niokolo-Koba National Park (Figure 3; Additional file 1). Collection sites and timing of expeditions were chosen to maximize the diversity of vespertilionid communities sampled throughout the year. Preliminary species determinations were based on morphological characters using the keys of Kingdon [59] and Rosevear [29]. Standard external body measurements were taken using callipers and the body mass was measured using a spring scale (data shown only for Pipistrellus rueppellii). The nomenclature generally followed Simmons [1], unless revised by subsequent taxonomic assessment (e.g. [8-10,15]). Chromosome preparations were completed in 48 specimens. Biological material of voucher specimens (skulls, skins, tissue samples for molecular analyses or whole animals), as well as the chromosome slides are deposited in the Institute of Vertebrate Biology (IVB), Academy of Sciences of the Czech Republic, Brno, Czech Republic. Sampling in Senegal was approved by the Senegal's National Parks General Management, Dakar (Specimens are listed in Additional file 1).

\section{Cytogenetics}

Chromosome preparations were completed in the field following the bone marrow direct method modified after Baker [90]. The standard non-differential Giemsa staining was performed. Attempts to apply differential staining failed, probably because of ageing of the slides that were prepared and stored in field conditions. Digital microimages of the metaphases were taken with the Zeiss AxioCam MRm or Olympus DP 30Win cameras attached to the Provis AX 70 Olympus microscope. Karyotypes were assembled with the software for cytogenetic analysis Ikaros (MetaSystems $\mathrm{GmbH}$, Germany) and final figures prepared with Corel PHOTO-PAINT 12 or X3 (Corel Corporation). The classification of chromosomes according to the position of the centromere followed published criteria [91].

\section{DNA extraction, PCR and sequencing}

Total genomic DNA was extracted from tissue samples stored in alcohol with DNeasy Blood \& Tissue Kit (Qiagen) or forensicGEM Saliva (ZyGEM). The genes were amplified by the polymerase chain reaction (PCR). Each $25 \mu \mathrm{l}$ reaction cocktail contained $12.5 \mu$ l of PPP Master Mix
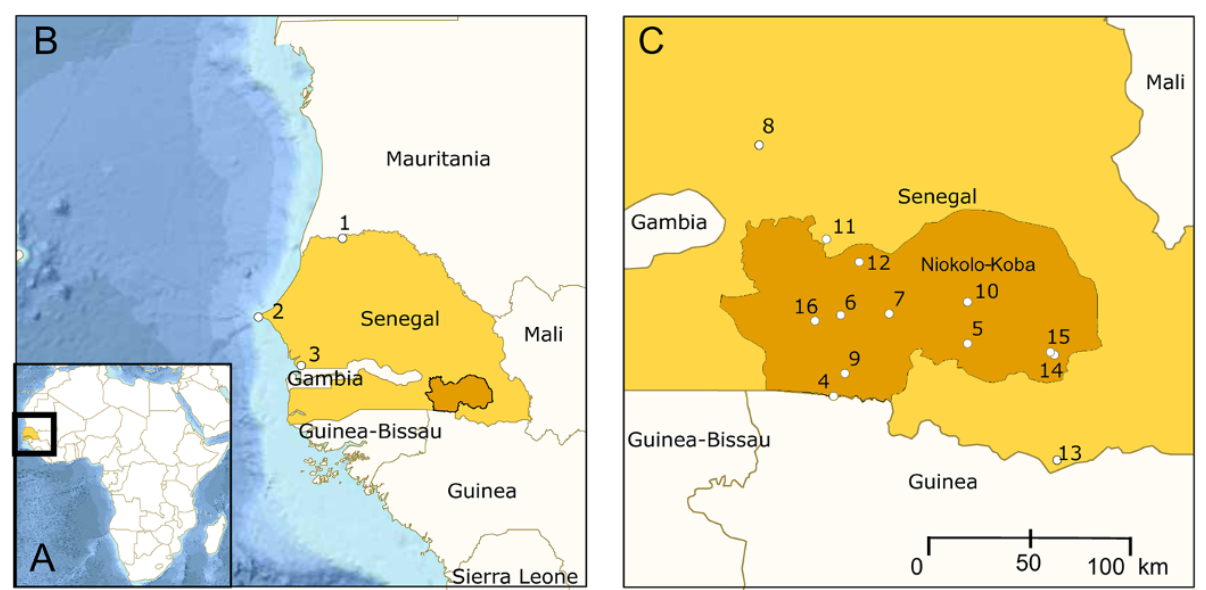

Figure 3 Sampling localities. A - map of Africa, bold square indicates the sampling area in West Africa; B - map of Senegal and Gambia with position of the area of the Niokolo-Koba National park (orange) and sampling localities: 1 - Mbilor, 2 - Hahn-Dakar, 3 - Bacadadgi; C - Niokolo-Koba National Park (orange): 4 - Gué de Sambaillou, 5 - Mont Assirik, 6 - Simenti + Camps de Lions, 7 - Lengué Kountou, 8 - Tambacounda + TambacoundaParc National de Niokolo-Koba, 9 - Dalaba, 10 - Niokolo, 11 - Niériko + Niériko-bridge, 12 - Dar Salam, 13 - Dindéfélo + Dindéfélo II, 14 - Mako-Camp, 15 - Mako, 16 - Gué de Damantan. The map was created with Planiglobe [89]. See Additional file 1 for coordinates of each locality. 
(2.5 U Taq purple DNA polymerase, $200 \mu \mathrm{M}$ of each dNTPs, 75 mM Tris-HCl, pH 8.8, $20 \mathrm{mM},\left(\mathrm{NH}_{4}\right)_{2} \mathrm{SO}_{4}$, $0.01 \%$ Tween 20), $1.5 \mu \mathrm{l} 2.5 \mathrm{mM}$ of $\mathrm{MgCl}_{2}$ and $8 \mu \mathrm{l}$ of PCR water (all from Top-Bio), $1 \mu \mathrm{l}$ of each primer $(0.4 \mu \mathrm{M})$ and $1 \mu \mathrm{l}$ of template DNA (all extracted DNA samples were diluted to a standardized concentration $2 \mathrm{ng} / \mu \mathrm{l})$. A specific primer set was designed for the joint amplification of $c y t b$ and $t R N A^{T h r}$ genes whereas published primer sets were used for the joint amplification of 12S, tRNA ${ }^{V a l}$ and $16 S$ [92] and for rag1 and rag2 genes ([93]; Table 2). Additionally, the $n d 1$ gene was sequenced from two individuals of Pipistrellus rueppellii using the PCR protocol and primers from Mayer et al. ([37]; Table 2), in order to test the genetic divergence of the Senegalese specimens from other populations. PCRs for all genes were performed as follows: initial denaturation for $2 \mathrm{~min}$ at $95^{\circ} \mathrm{C}$, denaturation for $30 \mathrm{~s}$ at $94^{\circ} \mathrm{C}$, annealing for $60 \mathrm{~s}$, extension for $90 \mathrm{~s}$ at $72^{\circ} \mathrm{C}$ and final extension for $10 \mathrm{~min}$ at $72^{\circ} \mathrm{C}$. The number of cycles and annealing temperatures of respective primers are reported in Table 2 .

PCR products were purified using Qiagen's QIAquick PCR Purification or Minielute kits or PCRExtract mini kit (5PRIME). The samples requiring gel extraction were cleaned with QIAquick or Minielute Gel Extraction kits from Qiagen. All samples were sequenced in both directions with the same PCR primers using BigDye Terminator sequencing chemistry (Applied Biosystems) on ABI sequencers. Sequences were assembled, checked by eye and edited in Geneious Pro version 5 ([94]; see Additional file 1 for GenBank Accession numbers). Additional sequences that represented all available vespertilionid and selected outgroup taxa were downloaded from GenBank ( $n=180$ taxa; Additional file 2). For some species, not all the genes were available from the same specimen; therefore, data of two or more individuals were used (Additional file 2). In the case of the genus Myotis, a reduced dataset was chosen to represent the main clades following Hoofer and Van Den Bussche [7].

\section{Phylogenetic analyses}

Nucleotide sequence alignment was performed using MAFFT version 5 [95] implemented in Geneious Pro version 5 [94]. The sequences of $12 S, t R N A^{V a l}$ and $16 S$ were each aligned in MAFFT version 6 (online at [96]), using the Q-INS-i method that takes into account the secondary structure of the ribosomal RNA. The resulting alignments were checked visually and manually corrected. The alignments of $12 S, t R N A^{\text {Val }}$ and $16 S$ sequences were compared with the alignment of Lack et al. [8] and ambiguous gap regions were removed, in order to prevent misidentification of homology and/or avoid overweighting of a single evolutionary event $[97,98]$. Coding gene sequences were translated to amino acids to confirm that they are not nuclear pseudogenes (which would contain frame shifts or premature stop codons).

To re-evaluate the morphological assignment of the Senegalese specimens, all 213 were sequenced for $c y t b$ (1,140 base pairs) and of these 209 were also successfully sequenced for the $t R N A^{T h r}$ (72 bp; Additional file 1). These data were supplemented with 148 other sequences of $c y t b$ and 11 of $t R N A^{T h r}$ from GenBank representing 148 taxa ( $n=361,1,212 \mathrm{bp}$; Additional file 2). (The length of the dataset is the maximum length available. Some sequences were shorter; represented by partial sequence data, or several taxa lacked genes entirely. The data matrix is represented in Additional file 1 and Additional file 2, which show the genes used for each taxon/specimen). These initial phylogenetic analyses of the concatenated data were performed by partitioning each gene and the $3^{\text {rd }}$ codon of $c y t b$ to account for different rates of evolution (Additional file 3). For this and all subsequent analyses, representatives of the families Cistugonidae, Miniopteridae, Molossidae and Natalidae were used to ensure adequate taxon sampling. For each phylogenetic analysis the outgroup was explicitly defined a priori (usually Natalus stramineus if available).

Bayesian phylogenetic analyses were performed using non-parallel and parallel versions 3.1.2 and 3.2.0 of

Table 2 Primers and details of PCRs used in the study

\begin{tabular}{|c|c|c|c|c|}
\hline Gene(s) & Primer name & Primer sequence & Annealing temperatures and no. of cycles & Reference \\
\hline \multirow[t]{2}{*}{ cytb and $t R N A^{T h r}$} & DK14169F & 5'-CCACGACTARTGACACGAAAAATC-3' & touchdown from 60 to $56^{\circ} \mathrm{C}$, then $55^{\circ} \mathrm{C}$ for 30 cycles & this study \\
\hline & DK15396R & 5'-CAGCTTTGGGTGTTGATGGT-3' & & this study \\
\hline \multirow[t]{2}{*}{ 12S, tRNA ${ }^{\mathrm{Val}}, 16 \mathrm{~S}$} & $12 \mathrm{C}$ & 5'-AAAGCAAARCACTGAAAATG-3' & $50^{\circ} \mathrm{C}, 36$ cycles & [92] \\
\hline & $12 \mathrm{G}$ & 5'- TTTCATCTITTCCTTGCGGTAC-3' & & [92] \\
\hline \multirow[t]{2}{*}{ rag1 } & RAG1F1705 & 5'-GCTITGATGGACATGGAAGAAGACAT-3' & touchdown from 60 to $58^{\circ} \mathrm{C}$, then $57^{\circ} \mathrm{C}$ for 33 cycles & {$[93]$} \\
\hline & RAG1R2864 & 5'-GAGCCATCCCTCTCAATAATTTCAGG-3' & & [93] \\
\hline \multirow[t]{2}{*}{$\operatorname{rag} 2$} & RAG2F220 & 5'-GATTCCTGCTA(CT)CT(TC)CCTCCTCT-3' & touchdown from 60 to $58^{\circ} \mathrm{C}$, then $57^{\circ} \mathrm{C}$ for 33 cycles & [93] \\
\hline & RAG2R995 & 5'-CCCATGTTGCTTCCAAACCATA-3' & & [93] \\
\hline \multirow[t]{2}{*}{ nd1 } & ND1F2 & 5'-GGCAGAGACCGGTAATTGCATAA-3' & $52^{\circ} \mathrm{C}, 30$ cycles & {$[37]$} \\
\hline & ND1R & 5'-GTATGGGCCCGATAGCTT-3' & & [37] \\
\hline
\end{tabular}


MrBayes software [51]. The GTR $+\mathrm{I}+\Gamma$ model was used for the Bayesian analysis and was selected for each gene dataset using the Akaike Information Criterion implemented in MrModeltest v2.3 [99]. Bayesian posterior probabilities were estimated using MCMC sampling in MrBayes. Two independent searches were performed, each set consisted of one cold and three heated chains (the temperature was left to default 0.2 in version 3.1.2 and 0.1 in 3.2.0), trees were sampled every 1000 generations and starting trees were random. The searches were set to stop when the average standard deviation of split frequencies decreased below 0.01 , burn-in value was 0.25 of all samples. The remaining trees were used to construct a $50 \%$ majority rule consensus tree.

Maximum likelihood analysis was performed with RAxML v 7.3.0 (Randomized Axelerated ML [100]) on the CIPRES Science Gateway [101] using the following settings: substitution model - GTR $+\Gamma, 500$ rapid bootstrap replicates, bootstrapping and $\mathrm{ML}$ search for the bestscoring tree performed in a single run. The automated stop was used initially to test the number of bootstraps required [102]. Conversion was reached at 250 bootstrap replicates, so we therefore conservatively choose to rerun the analysis with 500 bootstrap replicates.

Based on the initial BA and ML trees, representative specimens from the Senegalese populations were chosen (a maximum of up to three per species) to sequence four additional mitochondrial and two nuclear genes. We sequenced 20 individuals for rag1 and rag2 and 18 of the same individuals for $12 S$, $t R N A^{\text {Val }}$ and $16 S$. Repeated attempts to sequence two individuals for $12 S, t R N A^{V a l}$ and $16 S$ failed. We also sequenced two specimens of Pipistrellus rueppellii for $n d 1$ to confirm their species assignment with available GenBank data (Additional file 1).

RAxML analyses were used to construct single gene trees to assess if there was any gene conflict [103]. The sequences of each gene were trimmed to the same lengths, single triplet insertions were removed from rag sequences and only representatives with all respective genes were used to minimize the effect of missing data. We also compared combined selected mitochondrial gene phylogenies $\left(c y t b+12 S+t R N A^{\text {Val }}\right.$; ML and BA) versus a ML phylogeny based on nuclear genes (rag1 + rag2; for information on sequence lengths and $n$ of taxa and for selected subtrees see Additional files $5 \mathrm{~A}-\mathrm{C}$ ). In the single gene and combined analysis, we partitioned the $3^{\text {rd }}$ codon of $c y t b$ and $n d 1$, and each gene (if applicable). Subsequently, we concatenated all eight genes from 200 samples (20 specimens from Senegal, 180 taxa from GenBank - Additional file 2). In some cases, sequences of more individuals had to be combined. We increased taxon sampling even if this meant including taxa that had partial gene sequences or were missing data and only the ambiguous gap regions in $12 S, t R N A^{\text {Val }}$ and $16 S$ were removed. The missing data were treated as real missing data (not as unknown nucleotides, or gaps). The single gene datasets comprised maximally of the following lengths: $c y t b-1,140 \mathrm{bp}, t R N A^{T h r}-71 \mathrm{bp}$, $12 S$ - $920 \mathrm{bp}, t R N A^{\text {Val }}-64 \mathrm{bp}, 16 S$ - $82 \mathrm{bp}$, rag1 $1,123 \mathrm{bp}, \mathrm{rag} 2-1,308 \mathrm{bp}, n d 1-957 \mathrm{bp}$. The final length of the concatenated dataset was maximally 5,665 bp. The BA and ML analyses were completed as previously outlined, partitioning each gene and the $3^{\text {rd }}$ codon of $c y t b$ and $n d 1$ (Figure 2).

Additionally, we ran ML and BA analyses (partitioning the $3^{\text {rd }}$ codon) on the $217 n d 1$ gene sequences (900 bp) originally used by Mayer et al. [37] to test the influence of methodology, specifically on the phylogenetic position of $P$. rueppellii (Additional file 6).

Pairwise genetic distances between sequences were computed for $c y t b, 12 S$ and rag2 using Kimura two-parameter model of base substitution implemented in Phylip version 3.69 [35] using the default settings (program Dnadist; Additional file 4A-C).

\section{Availability of supporting data}

The data sets supporting the results of this article are included within the article (and its additional files).

\section{Additional files}

\begin{abstract}
Additional file 1: Phylogenetic tree to identify the 213 bats from Senegal marked by their IVB number. Bayesian phylogram presented based on the concatenated dataset of cytb and $t R N A^{T h r}$ genes with the addition of species from GenBank (1,212 bp; number of all taxa $n=361)$. The Bayesian analysis was run partitioned for genes and the $3^{\text {rd }}$ codon position for cytb, PP are indicated for each node. ML analysis was run on the same partitioned dataset, using RAxML GTR $+\Gamma$ model, bootstrap support values are indicated for each node. Nodes are considered supported when Bayesian posterior probabilities are $\geq 0.95$ and/or ML bootstrap proportions are $\geq 75 \%$. BA values are left and $M L$ values right of the hashes.

Additional file 2: List of nucleotide sequences obtained from GenBank used in this study. The table specifies the specimens and sequences used for each species. In some cases, data of two or more individuals were used to represent the respective species, because not all the genes were available from the same specimen. The table does not contain all the 217 specimens analysed for the nd 1 gene by Mayer et al. [37]. See their publication for the comprehensive list of these specimens. Here, we list only those sequences from their study used in the analyses, which also contained our data. The list of full references is at the bottom of the table.
\end{abstract}

Additional file 3: Tables of pairwise Kimura-2-parameter distances between sequences of selected genes of the specimens examined. Values represent percentage of different bases between sequences. Table A - Distances between the cytb gene sequences of 361 specimens (213 from Senegal and 148 from GenBank). Table B - Distances between the 125 gene sequences of 144 specimens ( 18 from Senegal and 126 from GenBank). Table C - Distances between the rag2 gene sequences of 140 specimens (20 from Senegal and 120 from GenBank). See Legends in the respective tables explaining the meaning of colours used.

Additional file 4: List of specimens collected in Senegal with sampling localities and GenBank Accession numbers of all sequences used. Asterisks indicate cases, in which the sequences for $t R N A^{T h r}$ were not obtained (and only the cytb gene was analysed). The 
acronym IVB used in specimens' numbers stands for the Institute of Vertebrate Biology, Academy of Sciences of the Czech Republic, Brno, Czech Republic, where the samples are deposited. The letter $\mathbf{S}$ was assigned to the specimens originating from Senegal. The seventh column indicates the specimens for which karyotypes were obtained and gives the diploid number of chromosomes (2n).

Additional file 5: Subtrees of phylogenetic trees based on single, mitochondrial and nuclear datasets showing phylogenetic positions differing from the eight-gene-tree. A - Subtree of the 125 gene tree representing 18 selected specimens from Senegal and GenBank data (920 bp, $n=144$ ), showing the position of Scotophilus and the relationships within the Glauconycteris clade. B - Subtree of the Bayesian concatenated $c y t b+12 S+t R N A^{\text {Val }}$ genes tree of 18 specimens from Senegal and GenBank data $(2,119 \mathrm{bp}, n=119)$ showing the position of Scotophilus and Nycticeius humeralis. C - Maximum likelihood concatenated rag 1 and rag 2 genes tree for 20 selected specimens from Senegal and GenBank data $(1,832 \mathrm{bp}, n=140)$ showing the position of Neoromicia and the relationships within the Glauconycteris clade. Nodes are considered supported when Bayesian posterior probabilities are $\geq 0.95$ and/or ML bootstrap proportions are $\geq 75 \%$. BA values are left and ML values right of the hashes.

Additional file 6: Part of the Bayesian nd1 gene tree based on data of Mayer et al. ([37]; $900 \mathrm{bp}, \boldsymbol{n}=\mathbf{2 1 7}$ ). Subtree showing the position of Pipistrellus rueppellii. Both ML and BA were run partitioned for the $3^{\text {rd }}$ codon. ML analysis was run using RAxML, GTR $+\lceil$ model. Nodes are considered supported when Bayesian posterior probabilities are $\geq 0.95$ and/or ML bootstrap proportions are $\geq 75 \%$. BA values are left and ML values right of the hashes.

\section{Competing interests}

The authors declare that they have no competing interests.

\section{Authors' contributions}

DK carried out the molecular genetic studies, karyotypic analyses, sequence alignment, phylogenetic analyses, participated in the design of the study, prepared all the tables and figures and wrote the manuscript. NI designed the molecular and phylogenetic parts of the study, coordinated the molecular laboratory works and phylogenetic computations, helped to interpret the data and draft the manuscript. PH participated in the design of the molecular and phylogenetic parts of the study and helped to draft the manuscript. PK managed the whole project, participated in the design of this study, collected the samples in the field, coordinated the preparation of chromosomal slides and organised specimen identifications from taxonomic experts. JZ designed the whole study, participated in the karyotype analyses and helped to draft the manuscript. All authors read and approved the final manuscript.

\section{Acknowledgments}

We thank Jaroslav Červený, Adam Konečný, Peter Vallo, Josef Bryja and other colleagues from the Institute of Vertebrate Biology AS CR, Brno, Czech Republic who collected the samples in the field in Senegal and Petr Benda (National Museum, Prague, Czech Republic) for morphological identification. Marie Rábová and Petr Ráb provided the software Ikarus for the chromosomal analysis. Josef Bryja and Hana Patzenhauerová enabled access to the $A B I$ sequencer. In addition, we are grateful to Michaela Nelson, for technical assistance during the laboratory work completed at the University of York.

Access to the MetaCentrum computing facilities was provided under the programme "Projects of Large Infrastructure for Research, Development, and Innovations" LM2010005 funded by the Ministry of Education, Youth, and Sports of the Czech Republic. We would also like to thank to the Department of Parasitology of the Faculty of Science, Charles University in Prague and to Libor Mořkovský from the Biodiversity Research Group for providing access to their computing facilities and for help and advice while using it.

Fieldwork and sampling in Senegal was approved by the Senegal's National Parks General Management, Dakar. The research was supported by grant IAA 6093404 by the Grant Agency of the Academy of Sciences of the Czech Republic, the laboratory work by GAUK 6110 by the Grant Agency of the
Charles University in Prague and SW-2012-265 206. Nancy Irwin was supported by a Daphne Jackson Fellowship sponsored by NERC.

\section{Author details}

'Department of Zoology, Faculty of Science, Charles University, Viničná 7, 12844 Praha 2, Czech Republic. 'Biology Department, University of York, Heslington, YO10 5DD York, UK. ${ }^{3}$ Institute of Vertebrate Biology, Academy of Sciences of the Czech Republic, Květná 8, 60365 Brno, Czech Republic. ${ }^{4}$ Department of Forest Protection and Game Management, Faculty of Forestry and Wood Sciences, Czech University of Life Sciences, Kamýcká 1176, 16521 Praha-Suchdol, Czech Republic.

Received: 11 March 2013 Accepted: 1 August 2013

Published: 12 August 2013

\section{References}

1. Simmons NB: Order Chiroptera. In Mammal species of the world. A taxonomic and geographic reference. 3rd edition. Edited by Wilson DE, Reeder DM. Baltimore: Johns Hopkins University Press; 2005:312-529.

2. Koopman KF: Chiroptera: systematics. In Handbook of zoology. Volume 8, Mammalia (60). Edited by Niethammer J, Schliemann H, Starck D. Berlin: Walter de Gruyter Press; 1994:1-217.

3. Simmons NB, Geisler JH: Phylogenetic relationships of Icaronycteris, Archaeonycteris, Hassianycteris, and Palaeochiropteryx to extant bat lineages, with comments on the evolution of echolocation and foraging strategies in Microchiroptera. Bull Am Mus Nat Hist 1998, 235:1-182.

4. Volleth M, Bronner G, Göpfert MC, Heller K-G, Von Helversen O, Yong H-S: Karyotype comparison and phylogenetic relationships of Pipistrellus-like bats (Vespertilionidae; Chiroptera; Mammalia). Chromosome Res 2001, 9:25-46.

5. Volleth M, Heller K-G: Phylogenetic relationships of vespertilionid genera (Mammalia: Chiroptera) as revealed by karyological analysis. Z Zoo/ Syst Evolut-forsch 1994, 32:11-34.

6. Zima J, Horáček I: Synopsis of karyotypes of vespertilionid bats (Mammalia: Chiroptera). Acta Univ Carol - Biol 1985, 1981:311-329.

7. Hoofer SR, Van Den Bussche RA: Molecular phylogenetics of the chiropteran family Vespertilionidae. Acta Chiropterol 2003, 5(Suppl):1-63.

8. Lack JB, Roehrs ZP, Stanley CE Jr, Ruedi M, Van Den Bussche RA: Molecular phylogenetics of Myotis indicate familial-level divergence for the genus Cistugo (Chiroptera). J Mammal 2010, 91:976-992.

9. Roehrs ZP, Lack JB, Van Den Bussche RA: A molecular phylogenetic reevaluation of the tribe Nycticeiini (Chiroptera: Vespertilionidae). Acta Chiropterol 2011, 13:17-31.

10. Roehrs ZP, Lack JB, Van Den Bussche RA: Tribal phylogenetic relationships within Vespertilioninae (Chiroptera: Vespertilionidae) based on mitochondrial and nuclear sequence data. J Mammal 2010, 91:1073-1092.

11. Monadjem A, Richards L, Taylor PJ, Stoffberg S: High diversity of pipistrelloid bats (Vespertilionidae: Hypsugo, Neoromicia, and Pipistrellus) in a West African rainforest with the description of a new species. Zool J Linn Soc 2013, 167:191-207.

12. Stadelmann B, Herrera LG, Arroyo-Cabrales J, Flores-Martínez JJ, May BP, Ruedi M: Molecular systematics of the fishing bat Myotis (Pizonyx) vivesi. J Mammal 2004, 85:133-139.

13. Stadelmann B, Jacobs DS, Schoeman C, Ruedi M: Phylogeny of African Myotis bats (Chiroptera, Vespertilionidae) inferred from cytochrome $b$ sequences. Acta Chiropterol 2004, 6:177-192

14. Stadelmann B, Lin L-K, Kunz TH, Ruedi M: Molecular phylogeny of New World Myotis (Chiroptera, Vespertilionidae) inferred from mitochondrial and nuclear DNA genes. Mol Phylogenet Evol 2007, 43:32-48.

15. Van Cakenberghe V, Seamark ECJ: African Chiroptera Report. Pretoria: AfricanBats; 2012:1-5902. http://www.africanbats.org.

16. Tate $\mathrm{GHH}$ : Results of the Archbold expeditions. No. 47. Review of the Vespertilionine bats, with special attention to genera and species of the Archbold collection. Bull Am Mus Nat Hist 1942, 80:221-297.

17. Hill JE, Harrison DL: The baculum in the Vespertilioninae (Chiroptera: Vespertilionidae) with a systematic review, a synopsis of Pipistrellus and Eptesicus, and the descriptions of a new genus and subgenus. Bull Brit Mus Nat Hist Zool 1987, 52:225-305.

18. Kawai K, Nikaido M, Harada M, Matsumura S, Lin L-K, Wu Y, Hasegawa M, Okada N: The status of the Japanese and East Asian bats of the genus Myotis (Vespertilionidae) based on mitochondrial sequences. Mol Phylogenet Evol 2003, 28:297-307. 
19. Frost DR, Timm RM: Phylogeny of plecotine bats (Chiroptera: "'Vespertilionidae'"): summary of the evidence and proposal of a logically consistent taxonomy. Am Mus Novit 1992, 3034:1-16.

20. Volleth M, Heller K-G, Fahr J: Phylogenetic relationships of three "Nycticeiini" genera (Vespertilionidae, Chiroptera, Mammalia) as revealed by karyological analysis. Mamm Biol 2006, 71:1-12.

21. Horáček I, Fejfar O, Hulva P: A new genus of vespertilionid bat from Early Miocene of Jebel Zelten, Libya, with comments on Scotophilus, and early history of vespertilionid bats (Chiroptera). Lynx, n.s. 2006, 37:131-150.

22. Hoofer SR, Van Den Bussche RA, Horáček I: Generic status of the American pipistrelles (Vespertilionidae) with description of a new genus. J Mammal 2006, 87:981-992.

23. Von Helversen O, Heller K-G, Mayer F, Nemeth A, Volleth M, Gombkötö P: Cryptic mammalian species: a new species of whiskered bat (Myotis alcathoe n. sp.) in Europe. Naturwissenschaften 2001, 88:217-223.

24. Zhang J-S, Han N-J, Jones G, Lin L-K, Zhang J-P, Zhu G-J, Huang D-W, Zhang S-Y: A new species of Barbastella (Chiroptera: Vespertilionidae) from North China. J Mammal 2007, 88:1393-1403.

25. Eger $\mathrm{J}$, Schlitter DA: A new species of Glauconycteris from West Africa (Chiroptera: Vespertilionidae). Acta Chiropterol 2001, 3:1-10.

26. Goodman SM, Jenkins RKB, Ratrimomanarivo FH: A review of the genus Scotophilus (Mammalia, Chiroptera, Vespertilionidae) on Madagascar, with the description of a new species. Zoosystema 2005, 27:867-882

27. Kruskop SV, Lavrenchenko LA: A new species of long-eared bat (Plecotus; Vespertilionidae, Mammalia) from Ethiopia. Myotis 2000, 38:5-17.

28. Kouame OML, Jengre N, Kobele M, Knox D, Ahon DB, Gbondo J, Gamys J, Egnankou W, Siaffa D, Okoni-Williams A, Saliou M: Key Biodiversity Areas identification in the Upper Guinea forest biodiversity hotspot. J Threat Taxa 2012, 4:2745-2752.

29. Rosevear DR: The Bats of West Africa. United Kingdom: British Museum of Natural History London; 1965:1-418.

30. Lelant $\mathrm{V}$, Chenaval $\mathrm{N}$ : Bilan succinct des espèces de chauves-souris inventoriées au Sénégal lors de la mission de novembre-décembre 2010. Electronic Report; 2011. http://storage.canalblog.com/44/45/738905/63677824.pdf.

31. Adam F, Hubert B: Chiroptères nouveaux pour le Sénégal. Mammalia 1972, 36:59-70.

32. Dorst J: A propos de quelques chiroptères du Sénégal, et description d'une forme nouvelle du genre Pipistrellus. Bull Mus Natl Hist Nat 1960, 31:471-474.

33. Verschuren J: XXII. Note sur les cheiroptères du Sénégal, principalement dans les parcs nationaux du Niokolo-Koba et du Delta du Saloum. Mém Inst Fr Afr Noire 1982, 92:307-313.

34. Aellen V: Le Parc National de Niokolo-Koba. II. Chiroptères. Mém Inst Fr Afr Noire 1956, 48A:23-34

35. Felsenstein J: PHYLIP - Phylogeny Inference Package (Version 3.2). Cladistics 1989, 5:164-166.

36. Baker RJ, Bradley RD: Speciation in mammals and the genetic species concept. J Mammal 2006, 87:643-662

37. Mayer F, Dietz C, Kiefer A: Molecular species identification boosts bat diversity. Front Zool 2007, 4:4

38. Kearney TC, Volleth M, Contrafatto G, Taylor PJ: Systematic implications of chromosome GTG-band and bacula morphology for Southern African Eptesicus and Pipistrellus and several other species of Vespertilioninae (Chiroptera: Vespertilionidae). Acta Chiropterol 2002, 4:55-76.

39. Bickham JW, Patton JC, Schlitter DA, Rautenbach IL, Honeycutt RL: Molecular phylogenetics, karyotypic diversity, and partition of the genus Myotis (Chiroptera: Vespertilionidae). Mol Phylogenet Evol 2004, 33:333-338.

40. McBee KM, Schlitter DA, Robbins RL: Systematics of African bats of the genus Eptesicus (Mammalia: Vespertilionidae). 2. Karyotypes of African species and their generic relationships. Ann Carnegie Mus 1987, 56:213-222.

41. Rautenbach IL, Bronner GN, Schlitter DA: Karyotypic data and attendant systematic implications for the bats of southern Africa. Koedoe 1993 36:87-104

42. Peterson RL, Nagorsen DW: Chromosomes of fifteen species of bats (Chiroptera) from Kenya and Rhodesia. Roy Ont Mus Life Sci Occ Pap 1975, 27:1-14.

43. Rautenbach IL, Fenton MB: Bats from Mana Pools National Park in Zimbabwe and the first record of Eptesicus rendallii from the country. $Z$ Säugetierk 1992, 57:112-115.

44. Ruedas LA, Lee TE Jr, Bickham JW, Schlitter DA: Chromosomes of five species of vespertilionid bats from Africa. J Mammal 1990, 71:94-100.
45. White TA, Bordewich M, Searle JB: A network approach to study karyotypic evolution: the chromosomal races of the common shrew (Sorex araneus) and house mouse (Mus musculus) as model systems. Syst Biol 2010, 59:262-276.

46. Faria $R$, Navarro A: Chromosomal speciation revisited: rearranging theory with pieces of evidence. Trends Ecol Evol 2010, 25:660-669.

47. Horn A, Basset P, Yannic G, Banaszek A, Borodin PM, Bulatova NS, Jadwiszczak K, Jones RM, Polyakov AV, Ratkiewicz M, Searle JB, Shchipanov NA, Zima J, Hausser J: Chromosomal rearrangements do not seem to affect the gene flow in hybrid zones between karyotypic races of the common shrew (Sorex araneus). Evolution 2012, 66:882-889.

48. Benda $P$, Hanák V, Andreas M, Reiter $A$, Uhrin M: Two new species of bats (Chiroptera) for the fauna of Libya: Rhinopoma hardwickii and Pipistrellus rueppellii. Myotis 2004, 41-42:109-124.

49. Veith $M$, Mucedda $M$, Kiefer A, Pidinchedda E: On the presence of pipistrelle bats (Pipistrellus and Hypsugo; Chiroptera: Vespertilionidae) in Sardinia. Acta Chiropterol 2011, 13:89-99.

50. Bergsten J: A review of long-branch attraction. Cladistics 2005, 21:163-193.

51. Huelsenbeck JP, Ronquist F: MRBAYES: Bayesian inference of phylogenetic trees. Bioinformatics 2001, 17:754-755

52. Roberts A: Descriptions of numerous new subspecies of mammals. Ann Transvaal Mus 1946, 20:303-328.

53. Kearney TC: Systematic revision of southern African species in the genera Eptesicus, Neoromicia, Hypsugo and Pipistrellus (Chiroptera: Vespertilionidae). Durban: PhD thesis. University of Kwa-Zulu-Natal; 2005:1-580.

54. Roberts A: Preliminary description of fifty-seven new forms of South African mammals. Mainly 38 from Vernay-Lang Kalahari Expedition, 1930. Ann Transvaal Mus 1932, 15:1-19.

55. Kock D: Identity of the African Vespertilio hesperida Temminck 1840 (Mammalia, Chiroptera, Vespertilionidae). Senckenberg Biol 2001, 81:277-283

56. Porter CA, Primus AW, Hoffmann FG, Baker RJ: Karyology of five species of bats (Vespertilionidae, Hipposideridae, and Nycteridae) from Gabon with comments on the taxonomy of Glauconycteris. Occ Pap Mus Tex Tech Univ 2010, 295:1-7

57. Lack JB, Van Den Bussche RA: Identifying the confounding factors in resolving phylogenetic relationships in Vespertilionidae. J Mammal 2010, 91:1435-1448.

58. Francis CM, Borisenko AV, Ivanova NV, Eger JL, Lim BK, Guillén-Servent A, Kruskop SV, Mackie I, Hebert PDN: The role of DNA barcodes in understanding and conservation of mammal diversity in Southeast Asia. PLOS ONE 2010, 5:e12575.

59. Kingdon J: The Kingdon Field Guide to African Mammals. Princeton: A\&C Black Publishers; 1997:478.

60. Csorba G, Son NT, Saveng I, Furey NM: Revealing cryptic bat diversity: three new Murina and redescription of M. tubinaris from Southeast Asia. J Mammal 2011, 92:891-904.

61. Agnarsson I, Zambrana-Torrelio CM, Flores-Saldana NP, May-Collado LJ: A time-calibrated species-level phylogeny of bats (Chiroptera, Mammalia). PLoS Curr 2011, 3, RRN1212.

62. Hanák V, Horáček I: Zur Südgrenze des Areals von Eptesicus nilssoni (Chiroptera: Vespertilionidae). Ann Naturhist Mus Wien 1985, 88:337-388.

63. Clare EL: Cryptic species? Patterns of maternal and paternal gene flow in eight Neotropical bats. PLOS ONE 2011, 6:e21460.

64. Nesi N, Kadjo B, Pourrut X, Leroy E, Pongombo Shongo C, Cruaud C, Hassanin A: Molecular systematics and phylogeography of the tribe Myonycterini (Mammalia, Pteropodidae) inferred from mitochondrial and nuclear markers. Mol Phylogenet Evol 2013, 66:126-137.

65. DeMenocal PB: African climate change and faunal evolution during the Pliocene-Pleistocene. Earth Planet Sci Lett 2004, 220:3-24.

66. Bonnefille R: Cenozoic vegetation, climate changes and hominid evolution in tropical Africa. Global Planet Change 2010, 72:390-411.

67. Nicolas V, Missoup AD, Denys C, Kerbis Peterhans J, Katuala P, Couloux A, Colyn M: The roles of rivers and Pleistocene refugia in shaping genetic diversity in Praomys misonnei in tropical Africa. J Biogeogr 2011, 38:191-207.

68. Maley J: The African rain forest: main characteristics of changes in vegetation and climate from the Upper Cretaceous to the Quaternary. Proc Roy Soc Edinburgh 1996, 104B:31-73.

69. Lorenzen ED, Masembe C, Arctander P, Siegismund HR: A long-standing Pleistocene refugium in southern Africa and a mosaic of refugia in East 
Africa: insights from mtDNA and the common eland antelope. J Biogeogr 2010, 37:571-581.

70. Booth AH: The Niger, the Volta and the Dahomey Gap as geographic barriers. Evolution 1958, 12:48-62

71. Salzmann U, Hoelzmann P: The Dahomey Gap: an abrupt climatically induced rain forest fragmentation in West Africa during the late Holocene. The Holocene 2005, 15:190-199.

72. Booth AH: The Dahomey Gap and the mammalian fauna of the West African Forest. Rev Zool Bot Afr 1954, 50:305-314.

73. Nicolas V, Quérouil S, Verheyen E, Verheyen W, Mboumba JF, Dillen M, Colyn M: Mitochondrial phylogeny of African wood mice, genus Hylomyscus (Rodentia, Muridae): Implications for their taxonomy and biogeography. Mol Phylogenet Evol 2006, 38:779-793.

74. Fuchs J, Crowe TM, Bowie RCK: Phylogeography of the fiscal shrike (Lanius collaris): a novel pattern of genetic structure across the arid zones and savannas of Africa. J Biogeogr 2011, 38:2210-2222.

75. Lorenzen ED, Arctander P, Siegismund HR: Three reciprocally monophyletic mtDNA lineages elucidate the taxonomic status of Grant's gazelles. Conservation Genetics 2008, 9:593-601.

76. Muwanika VB, Nyakaana S, Siegismund HR, Arctander P: Phylogeography and population structure of the common warthog (Phacochoerus africanus) inferred from variation in mitochondrial DNA sequences and microsatellite loci. Heredity 2003, 91:361-372.

77. Djossa BA, Sinsin BA, Kalko EKV, Fahr J: Inventory of bat species of Niaoul Forest, Bénin, and its bearing on the significance of the Dahomey Gap as a zoogeographic barrier. African Bat Conservation News 2008, 15:4-6.

78. Robbins CB: The Dahomey gap - a reevaluation of its significance as a faunal barrier to West African high forest mammals. Bull Carnegie Mus nat Hist 1978, 6:168-174.

79. Weber N, Kalko EKV, Fahr J: A first assessment of home range and foraging behaviour of the African long-tongued bat Megaloglossus woermanni (Chiroptera: Pteropodidae) in a heterogeneous landscape within the Lama Forest Reserve, Benin. Acta Chiropterol 2009, 11:317-329.

80. Larsen RJ, Knapp MC, Genoways HH, Khan FAA, Larsen PA, Wilson DE, Baker RJ: Genetic Diversity of Neotropical Myotis (Chiroptera: Vespertilionidae) with an Emphasis on South American Species. PLOS ONE 2012, 7:e46578.

81. Eaton MJ, Martin A, Thorbjarnarson J, Amato G: Species-level diversification of African dwarf crocodiles (Genus Osteolaemus): A geographic and phylogenetic perspective. Mol Phylogenet Evol 2009, 50:496-506.

82. Hausberger B, Kimpel D, Van Neer A, Korb J: Uncovering cryptic species diversity of a termite community in a West African savanna. Mol Phylogenet Evol 2011, 61:964-969.

83. Vallo P, Benda P, Červený J, Koubek P: Conflicting mitochondrial and nuclear paraphyly in small-sized West African house bats (Vespertilionidae). Zool Scr 2013, 42:1-12.

84. Vallo P, Benda P, Martínková N, Kaňuch P, Kalko EKV, Červený J, Koubek P: Morphologically uniform bats Hipposideros aff. ruber (Hipposideridae) exhibit high mitochondrial genetic diversity in southeastern Senegal. Acta Chiropterol 2011, 13:79-88

85. Koubínová D, Sreepada KS, Koubek P, Zima J: Karyotypic variation in rhinolophid and hipposiderid bats (Chiroptera: Rhinolophidae, Hipposideridae). Acta Chiropterol 2010, 12:393-400.

86. Barratt EM, Deaville R, Burland TM, Bruford MW, Jones G, Racey PA, Wayne RK: DNA answers the call of pipistrelle bat species. Nature 1997, 387:138-139.

87. Kingston T, Rossiter SJ: Harmonic-hopping in Wallacea's bats. Nature 2004, 429:654-657.

88. Hulva P, Fornůsková A, Chudárková A, Evin A, Allegrini B, Benda P, Bryja J: Mechanisms of radiation in a bat group from the genus Pipistrellus inferred by phylogeography, demography and population genetics. Mol Ecol 2010, 19:5417-5431.

89. Planiglobe. www.planiglobe.com.

90. Baker RJ: Karyotypic trends in bats. In Biology of Bats. Volume 1. Edited by Wimsatt WA. New York: Academic Press; 1; 1970:65-96.

91. Hsu TC, Benirschke K: An Atlas of Mammalian Chromosomes. Volumes 1-10. Berlin Heidelberg - New York: Springer Verlag; 1967-1977.

92. Springer MS, Hollar LJ, Burk A: Compensatory substitutions and the evolution of the mitochondrial $12 \mathrm{~S}$ rRNA gene in mammals. Mol Biol Evol 1995, 12:1138-1150.

93. Teeling EC, Scally M, Kao DJ, Romagnoli ML, Springer MS, Stanhope MJ: Molecular evidence regarding the origin of echolocation and flight in bats. Nature 2000, 403:188-192.
94. Drummond AJ, Ashton B, Buxton S, Cheung M, Cooper A, Duran C, Field M, Heled J, Kearse M, Markowitz S, Moir R, Stones-Havas S, Sturrock S, Thierer T, Wilson A: Geneious V5.4; 2011. http://www.geneious.com.

95. Katoh K, Misawa K, Kuma K, Miyata T: MAFFT: a novel method for rapid multiple sequence alignment based on fast Fourier transform. Nucleic Acids Res 2002, 30:3059-3066.

96. MAFFT version 6. http://mafft.cbrc.jp/alignment/server/.

97. Warnow T: Standard maximum likelihood analyses of alignments with gaps can be statistically inconsistent. PLOS Curr 2012, 4:RRN1308.

98. Talavera G, Castresana J: Improvement of phylogenies after removing divergent and ambiguously aligned blocks from protein sequence alignments. Syst Biol 2007, 56:564-577.

99. Nylander JAA: MrModeltest 2.3. Program distributed by the author. Uppsala University: Evolutionary Biology Centre; 2004

100. Stamatakis A: RAxML-VI-HPC: maximum likelihood-based phylogenetic analyses with thousands of taxa and mixed models. Bioinformatics 2006, 22:2688-2690

101. Miller MA, Pfeiffer W, Schwartz T: Creating the CIPRES Science Gateway for inference of large phylogenetic trees. In Proceedings of the Gateway Computing Environments Workshop: 14 November. LA: GCE New Orleans; 2010:1-8.

102. Pattengale ND, Alipour M, Bininda-Emonds ORP, Moret BME, Stamatakis A: How many bootstrap replicates are necessary? J Comput Biol 2010, 17:337-354.

103. Degnan JH, Rosenberg NA: Gene tree discordance, phylogenetic inference and the multispecies coalescent. Trends Ecol Evol 2009, 24:332-340.

doi:10.1186/1742-9994-10-48

Cite this article as: Koubínová et al:: Hidden diversity in Senegalese bats and associated findings in the systematics of the family Vespertilionidae. Frontiers in Zoology 2013 10:48.

\section{Submit your next manuscript to BioMed Central and take full advantage of:}

- Convenient online submission

- Thorough peer review

- No space constraints or color figure charges

- Immediate publication on acceptance

- Inclusion in PubMed, CAS, Scopus and Google Scholar

- Research which is freely available for redistribution 